\title{
Capillary Gas Chromatography-Mass Spectrometry (CGC-MS) Analysis and Antioxidant Activities of Phenolic and Components of Guarana and Derivatives
}

\author{
Eugenia M. Kuskoski ${ }^{1}$, José J. Rios ${ }^{2}$, Julia Martín Bueno ${ }^{3}$, Roseane Fett $^{1}$, Ana M. Troncoso ${ }^{4}$ and \\ Agustín G. Asuero*,3 \\ ${ }^{1}$ Department of Food Science, University of Santa Catarina, Florianópolis, 88034.001, S.C., Brasil \\ ${ }^{2}$ Food Characterization Quality Department, Instituto de la Grasa (C.S.I.C.), 41012-Seville, Spain \\ ${ }^{3}$ Department of Analytical Chemistry, University of Seville, 41012-Seville, Spain \\ ${ }^{4}$ Department Food Science and Toxicology, University of Seville, 41012-Seville, Spain
}

\begin{abstract}
The GC-MS analysis of phenolic compounds present in guarana (Paullinia cupana), an important product of the Amazonian forest consumed in supplements or in soft drinks has been the subject of study. The therapeutic properties and possible protective effects reported for guarana and derivative products could be associated with the antioxidant activity of their phenolics content. The purpose of this study is i) to provide molecular structural information about the composition of guarana in phenolics; ii) to ascertain the effect of solvent type on the extraction procedure; and iii) to determine the antioxidant activity of powders, pericarp, pulp seeds, capsules and bar from Paullinia cupana, as oxygen radical absorbance capacity with fluorescein $\left(\mathrm{ORAC}_{\mathrm{FL}}\right)$. Three more phenolic compounds, Quercetin, $(+)$-Catechin and $(-$ )-Epicatechin have been identified in this report as trimethylsilyl (TMS) derivatives. The amount of total phenolics found in plant materials containing guarana varied from 25.10 to $124.99 \mathrm{mg}$ of gallic acid/g dry sample whereas that the antioxidant activity ranged from 441.5 to $1468.3 \mu \mathrm{mol} \mathrm{TEAC} / \mathrm{g}$ dry sample. A high correlation was found between the estimated phenolic contents and the TEAC values $(r=0.937, P<0.01)$ for all the types of guarana samples tested.
\end{abstract}

Keywords: Guarana (Paullinia cupana), phenolic compounds, capillary gas chromatography-mass spectrometry, antioxidant activity.

\section{INTRODUCTION}

A number of studies have shown that chronic diseases such as cancer, cardiovascular, inflammatory, and neurodegenerative pathologies, and aging, are associated [13] with oxidative stress, a metabolic condition that causes cell degeneration. Consumption of phytochemicals in the diet, especially phenolics, has been closely connected [4-6] with the reduced risk of diseases. Fruits and vegetables, as well as plant beverages such as tea and coffee contributes [7, $8]$ to the dietary intake of antioxidants.

The guarana, a plant Paullinia cupana native species belonging to the family of the Sapindaceas, from the central Amazonian, exists in two varieties: sorbilis and typical. It produces a fruit that it is spherical, blackish and brilliant, assuming a form of capsule in whose interior there is only a seed that when it matures changes from green to red-orange [9]. Once the complete maturity is reached, the "white of the eye", botanically an aril of mealy consistency, is chosen. Then it is rubbed of manually and the seeds are roasted to facility the removal of the glossy, tough and dark brow seed coat (pericarp) and the later grinding of the kernels in a hardwood mortar [10-12].

*Address correspondence to this author at the Department of Analytical Chemistry, University of Seville, 41012-Seville, Spain; Tel: 34954556746; Fax: 34954556749; E-mail: asuero@us.es
Paullinia cupana (guarana) has been the focus of considerable attention due to its high caffeine content and pharmacological activity and behaves as a tonic and stimulant of the nervous system [13] an aphrodisiac [14] and beneficial in memory performance [15]. Guarana has been used to treat chronic diarrhea, neuralgia and dysentery [16], and to reduce the body weight [17]. Guarana have indications in cases of depression, in arteriosclerosis, as tonic of the heart, as anti-inflammatory, showing also antioxidant action (inhibitor of lipid peroxidation process) [9]. It is also reputed to be a cardiovascular drug and to prevent atherosclerosis (guarana extracts inhibited platelet aggregation in rabbits following either intravenous or oral administration) [9]. Some guarana studies have been undertaken with the purpose [18, 19] of to determine adulterations and to monitorize the quality control of guarana products in the phytopharmaceutical industry. It has been shown that guarana seed extracts have antioxidant and antimicrobial properties $[20,21]$.

In Latin America, mainly in Brazil, a great interest in the field of food science has aroused because of the use of guarana as a flavouring agent in beverages such as "guarana soda", of an elevated consumption in the population. More recently, guarana has been employed in the form of powder, tablets and jams, either pure or in association, as a dietetic product for slimming. The capsules and powders added to 
juices and other drinks are also products of great consumption [9].

Many separation techniques such as gas-liquid chromatography (GLC), high-performance liquid chromatography (HPLC), and capillary electrophoresis (CE) have been proposed to separate and identify phenolic compounds [22, 23]. HPLC and CE, especially coupled a with photodiode array detector, do not require derivatization prior to qualitative and quantitative analysis. Hence, they have become the most commonly used techniques for the analysis of phenolic compounds in plants. Nevertheless, they do not often provide satisfactory performance, and the UVvisible spectrum does not supply [24] sufficient evidence for unambiguous identification. For these reasons, capillary gas chromatography combined with mass spectrometry (CGCMS) is a useful alternative technique, which can provide sufficient data for full structural analysis. More generally, it may be used to determine molecular masses thus establishing the respective substitution pattern on the phenolic ring(s). Trimethylsilyl (TMS) derivatives of phenolic compounds were prepared prior to CGC-MS analysis [25].

In the present study the method of CGC-MS was used for the analysis of major phenolic substances present in seeds of the guarana. The effectiveness of different solvents in extracting phenolics from guarana toasted seed powder has also been studied. Finally, the antioxidant capacities of powders, pericarp, pulp seeds, capsules and bar from Paullinia cupana (guarana) have been evaluated.

\section{MATERIALS AND METHODS}

\subsection{Reagents}

All solvents and reagents from various suppliers were of the highest purity needed for each application. The FolinCiocalteu reagent and sodium carbonate were purchased from Sigma ${ }^{\circledR}$ (St. Louis, MO). Gallic acid, 6-hydroxy2,5,7,8-tetramethylchroman-2-carboxylic acid (Trolox), Fluorescein and 2,2'-azobis (2-amidinopropane) dihydrochloride (AAPH) were purchased from Aldrich Chem. Co. (Dorset, UK).

\subsection{Plant Material}

The guarana (seeds, pericarp, seed powder, capsules and bar) were obtained from different sources. The seeds and seed powdered dry were obtained from Brazil Amazonic producers in Ariquemes, RO (63. $02^{\prime} 27^{\prime \prime} \mathrm{W}$ and $9^{\circ} 54^{\prime} 48^{\prime \prime}$ $\mathrm{S})$, Alta Floresta, MT (56 $06^{\prime} 10^{\prime \prime} \mathrm{W}$ and $\left.9^{\circ} 52^{\prime} 32^{\prime \prime} \mathrm{S}\right)$ and

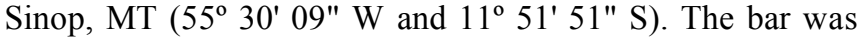

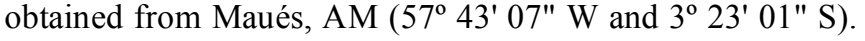
The guarana capsules were obtained at pharmacy shops in Florianópolis, Brazil. The samples were transported to the University of Seville and stored frozen until used. The seeds were separated from the pericarp and pulp seed. Processing steps described above were applied to three replicates $(n=3)$ in all samples studied (thirty). All samples were dried previous analysis and resulted were expressed en dry weight (DW).

\subsection{Sample Preparation and Derivatization}

Guarana seed powder dry was de-oiled with hexane (one part powder to 10 parts of hexane, w/v). After shaking the mixture for $10 \mathrm{~min}$ at room temperature, the liquid was separated from the solid by vacuum filtration through a sintered glass filter (Pyrex $\left.{ }^{\circledR} 10-15 \mathrm{M}\right)$. The solid residue was evenly distributed over a tray and kept under the hood in the dark to evaporate the hexane. The extraction method used for dried samples is described in that follows: Twenty milliliters of $60 \%$ aqueous methanol containing BHT $\left(1 \mathrm{~g} \mathrm{~L}^{-1}\right)$ was added to $2.0 \mathrm{~g}$ of dried sample. Then $5 \mathrm{~mL}$ of $6 \mathrm{M} \mathrm{HCl}$ were added. The mixture was stirred carefully. In each sample nitrogen was bubbled for ca. 40-60 s. The extraction mixture was then sonicated for $15 \mathrm{~min}$ and refluxed in a water bath at $90{ }^{\circ} \mathrm{C}$ for $2 \mathrm{~h}$. The mixture was then extracted with $30 \mathrm{~mL}(3$ $\times 10 \mathrm{~mL}$ ) ethyl acetate. The organic layer was collected and reduced to $10 \mathrm{~mL}$ by rotary evaporation $\left(37^{\circ} \mathrm{C}\right)$ and centrifuged for $10 \mathrm{~min}$. Anhydrous $\mathrm{Na}_{2} \mathrm{SO}_{4}$ was then added to remove residual moisture. Phenolic extracts were evaporated to dryness under a nitrogen stream and immediately derivatized with $100 \mu \mathrm{L}$ of a mixture of HMDS+DMCS in pyridine (3:1:9) and aliquots of 3 microliters were injected on split mode.

\subsection{GC-MS and GC-SIM-MS Instrumental Analysis}

The GC-Ion trap-MS experiments were performed using a Trace GC 2000 gas chromatograph coupled to a Polaris-Q Ion trap mass spectrometer (ThermoFinnigan, Austin, TX, USA) equipped with an AS 2000 autosampler operating in full scan mode and in selective ion monitoring (SIM) mode only for identification purposes. The column used was a Zebron ZB-5ms (Phenomenex, Torrance, CA, USA) fused silica capillary column $(30 \mathrm{~m}$ long x $0.25 \mathrm{~mm}$ I.D. $x \quad 0.25$ film thickness). The oven temperature was programmed as follow: the initial temperature was held for $5 \mathrm{~min}$ at $150^{\circ} \mathrm{C}$ and then from 150 to $295^{\circ} \mathrm{C}$ at $3^{\circ} \mathrm{C} / \mathrm{min}$ and maintained for $18 \mathrm{~min}$. Injector temperature was set to $300^{\circ} \mathrm{C}$. Carrier gas was Helium at $1 \mathrm{~mL} / \mathrm{min}$ in constant flow mode. The MS operating conditions were the following: ion source and transfer line temperatures 200 and $290^{\circ} \mathrm{C}$, respectively. The instrument was tuned in EI positive mode using perfluorotributylamine (FC-43) according to manufacturer's recommendations in order to achieve the best sensitivity. Parameters such as automatic gain control (AGC) and multiplier $(1150 \mathrm{~V}, 105$ gain) were set by automatic tuning. The electron energy was $70 \mathrm{eV}$ and the emission current 250 A. Samples were analyzed as TMS ether derivatives. Xcalibur version 1.4 software was used for data acquisition and processing of the results. Each determination was carried out in duplicate.

\subsection{Extraction of Polyphenolic Compounds from Guarana Seeds}

Solvents containing different volumes of de-ionized water methanol or acetone were used to determine the effectiveness of solvent type on the extraction of phenolics from guarana seed powder. Known weights of guarana seed powder were mixed with solvent at a ratio of 1:10 (w/v). The mixture was sonicated for $15 \mathrm{~min}$, and shaken for $30,60 \mathrm{~min}$ and $24 \mathrm{~h}$ at room temperature. Then, the mixture was centrifuged at $4{ }^{\circ} \mathrm{C}$ for $20 \mathrm{~min}$ at $5000 \mathrm{rpm}$. Supernatants were filtered through a funnel with glass wool, which was washed with 3-4 $\mathrm{mL}$ of solvent. The volumes of filtered supernatants were recorded to calculate total phenolics. 


\subsection{Determination of Total Phenolics Content}

Total phenol content of guarana ethanol extracts was determined using the Folin-Ciocalteu assay [26]. Briefly, a $100 \mu \mathrm{L}$ aliquot of ethanol extract was assayed with $500 \mu \mathrm{L}$ Folin reagent and $1.5 \mathrm{~mL}$ sodium carbonate $(20 \%, \mathrm{w} / \mathrm{v})$. The mixture was vortexed and diluted with water to a final volume of $10 \mathrm{~mL}$. After incubation for $30 \mathrm{~min}$ at room temperature, the absorbance was read at $765 \mathrm{~nm}$ in a cuvette of $1 \mathrm{~cm}$ and total phenols in the guarana extract were expressed as gallic acid equivalents (GAE), using a calibration curve of a freshly prepared gallic acid solution. For the gallic acid, the absorbance versus concentration curve is described by the equation $\mathrm{y}=0.0013 \mathrm{x}-0.0074\left(\mathrm{R}^{2}\right.$ $=0.9986)$.

\subsection{Determination of Catechol Content}

The quantitative analysis of catechol in guarana seeds was performed by a spectrophotometric method [27] based on the reaction of $p$-aminophenol with catechol giving rise to indophenol dye-like species. For the calibration curve, the $p$ aminophenol solution was prepared at $1 \mathrm{mM}$ using $0.1 \mathrm{M}$ $\mathrm{HCl}$ aqueous solution. Catechol standard solution was prepared at $0.01 \mathrm{M}$ in $95 \%$ ethanol. The calibration curve was prepared by loading, separately, in six $10 \mathrm{~mL}$ volumetric flasks $3.0 \mathrm{~mL}$ of $2 \%(\mathrm{w} / \mathrm{v}) \mathrm{NaOH}$ solution, $3.0 \mathrm{~mL}$ of $\mathrm{p}$ aminophenol solution and 0.0, 10.0, 25.0, 50.0, 75.0 and 100 $\mu \mathrm{L}$ of catechol standard solution. The final volume was completed with ethanol and the absorbance was measured [27] at $586 \mathrm{~nm} 1 \mathrm{~min}$ after adding catechol. As for catechol determination, we used the standard addition method because of the interference of the matrix. Three $\mathrm{mL}$ of $2 \%$ (w/v) $\mathrm{NaOH}$ solution and $3.0 \mathrm{~mL}$ of p-aminophenol were added to six $10 \mathrm{~mL}$ volumetric flasks. Then $1 \mathrm{~mL}$ of guarana ethanol extract and the adequate catechol standard solution volume $0.0,10.0,25.0,50.0,75.0$ and $100 \mu \mathrm{L}$ were added. The final volume was completed with ethanol and the absorbance was measured [27] at $586 \mathrm{~nm}$ run 1 min after the addition of catechol.

\subsection{Antioxidant Activities. ORAC Assay}

The method of Davalos, Gómez-Cordovés and Bartolomé [28] and Prior et al., [29] was modified as follows: The reaction was carried out in $75 \mathrm{mM}$ phosphate buffer $(\mathrm{pH}$ 7.4), and the final reaction mixture was $600 \mu \mathrm{L}$. Sample (60 $\mu \mathrm{L})$ and fluorescein $(360 \mu \mathrm{L} ; 14 \mu \mathrm{M}$, final concentration) solutions were placed in the well of the microcell $(1 \mathrm{~mL})$. The mixture was preincubated for $15 \mathrm{~min}$ at $37{ }^{\circ} \mathrm{C}$. AAPH solution (180 $\mu \mathrm{L} ; 4,8 \mathrm{mM}$, final concentration) was added rapidly. The microcell was immediately placed in the reader and the fluorescence recorded every minute for $80 \mathrm{~min}$. A blank (FL + AAPH) using phosphate buffer instead of the antioxidant solution and eight calibration solutions using Trolox (1-8 $\mu \mathrm{M}$, final concentration) as antioxidant were also carried out in each assay. All the reaction mixtures were prepared in duplicate, and at least three independent assays were performed for each sample. The final ORAC values were calculated by using a regression equation between the Trolox concentration and the net area under the FL decay curve and were expressed as Trolox equivalents as micromole per liter or per gram. The area under curve (AUC) was calculated as:
$\mathrm{AUC}=\left(0.5+f_{5} / f_{0}+f_{10} / f_{0}+f_{15} / f_{0}+f_{20} / f_{0}+\ldots . .+f_{75} / f_{0}+f_{80} / f_{0}\right) \times 5$ where $f_{0}$ is the initial fluorescence reading at $0 \mathrm{~min}$ and $f_{\mathrm{i}}$ is the fluorescence reading at time $i$. The relative ORAC value (Trolox equivalents) was calculated as relative ORAC value $(\mu \mathrm{M})=\left[20 K\left(\mathrm{AUC}_{\text {sample }}-\mathrm{AUC}_{\text {Blank }}\right) /\left(\mathrm{AUC}_{\text {Trolox }}-\right.\right.$ $\left.\mathrm{AUC}_{\mathrm{Blank}}\right)$ ]. Were $K=$ sample dilution factor. Raw data were exported from the Fluostar Galaxy software to an Excel (Microsoft, Roselle, IL) spreadsheet.

\subsection{Statistical Analyses}

All tests were carried out in duplicate. Data were analyzed using the STATISTICA'99 ${ }^{\circledR}$ version software package. Data on antioxidant activity and phenolic content underwent a correlation test. Anova/Manova comparison test was performed to determine significant differences at $P=0.05$. Regression analysis [30-31] to determine ORAC values was performed by Microsoft Excel.

\section{RESULTS AND DISCUSSION}

\subsection{Extraction of Phenolic Compounds from Guarana Seed}

Ethanol alone or de-ionized water alone was ineffective as a solvent for the extraction of phenolic compounds from guarana seed powder. Total phenol content of ethanol extracts from guarana seed powder when extracted with solvent containing $50 \%, 60 \%$ or $70 \%$ ethanol $(95 \% \mathrm{v} / \mathrm{v})$ in water was about $72 \mathrm{mg}$ gallic acid equivalent (GAE)/g seed powder $(P>0.05)$ (Fig. 1). The trend of absorbance at $280 \mathrm{~nm}$ for extracts with ethanol was similar to that of the total phenols, which indicates that the absorbance of the extract is directly related to the extractable polyphenols in solution.

High and significant correlation coefficients were observed among total phenol content, absorbance at $280 \mathrm{~nm}$ and antioxidant activity of the ethanol supernatants. Correlation coefficient between total phenol content and absorbance at $280 \mathrm{~nm}$ was $0.940(P<0.01)$. Supernatants from a solvent containing $50 \%, 60 \%$ or $70 \%$ methanol in water yielded about $63 \mathrm{mg}$ GAE per g guarana seed. This was the highest concentration in the extract compared with the other methanol-water mixtures (Fig. 2). Increasing water in the mixture from $70 \%$ to $100 \%$ significantly reduced the amount of phenolic compounds extracted $(P<0.05)$. Methanol only was insufficient for the extraction of phenolic compounds from guarana seed powder. Extracts using solvent containing $50 \%$ or $60 \%$ methanol have the highest absorbance at $280 \mathrm{~nm}(P<0.05)$ (Fig. 2). Unlike ethanolwater solvents, methanol-water solvents appear to show differences in solvent concentration optimum when evaluated as total phenolics and absorbance at $280 \mathrm{~nm}$. Total phenol contents of methanol-water extracts were correlated with absorbance at $280 \mathrm{~nm}(\mathrm{r}=0.958, P<0.01)$.

The effects of shaking time and solvent on the extraction of phenolic compounds from guarana seed were also studied. Results (Fig. 3) indicated that shaking the mixture of guarana seed powder in $70 \%$ methanol $(\mathrm{v} / \mathrm{v})$ at room temperature for $30 \mathrm{~min}$ or $60 \mathrm{~min}$ had no significant effect on the total phenol contents of the extracts from guarana seed $(P>0.05)$.

Among acetone-water mixtures as solvents, those containing $50 \%, 60 \%$ and $70 \%$ acetone by volume showed 


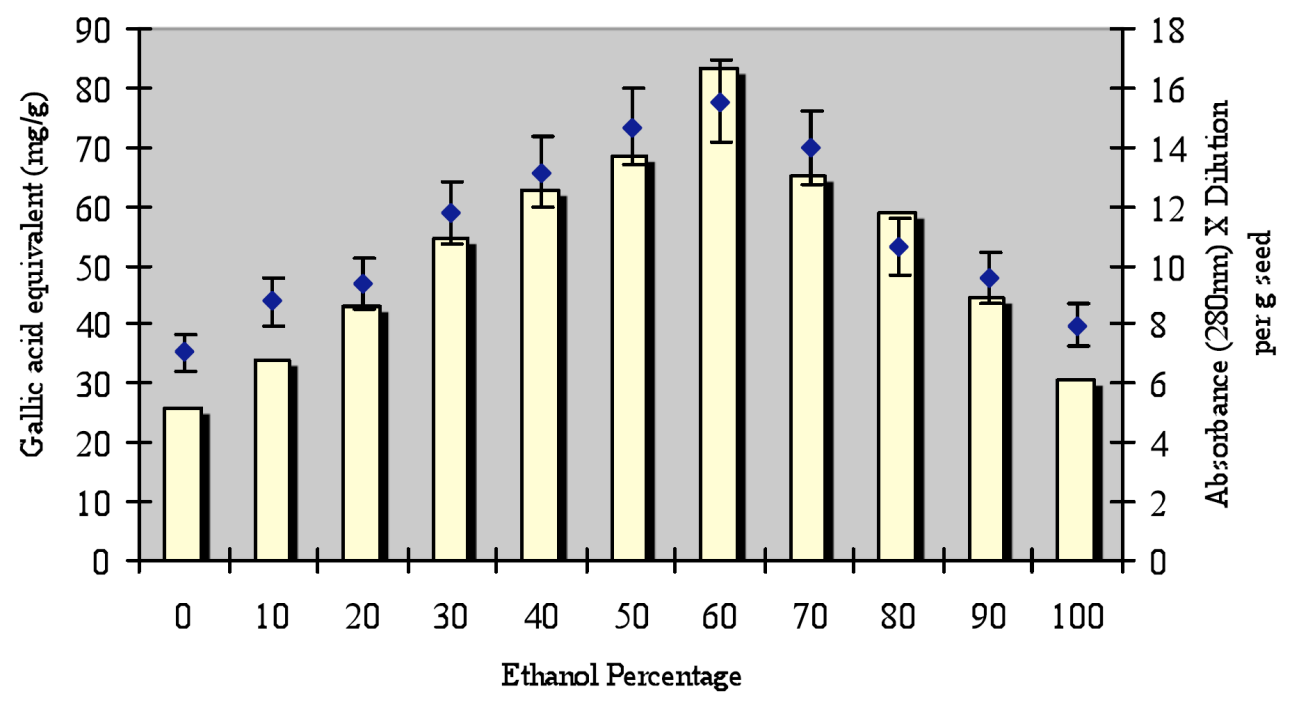

Fig. (1). Effect of ethanol $(95 \% \mathrm{v} / \mathrm{v})$ on the total phenol contents and absorbances at $280 \mathrm{~nm}$ of supernatants from dried and ground guarana seeds.

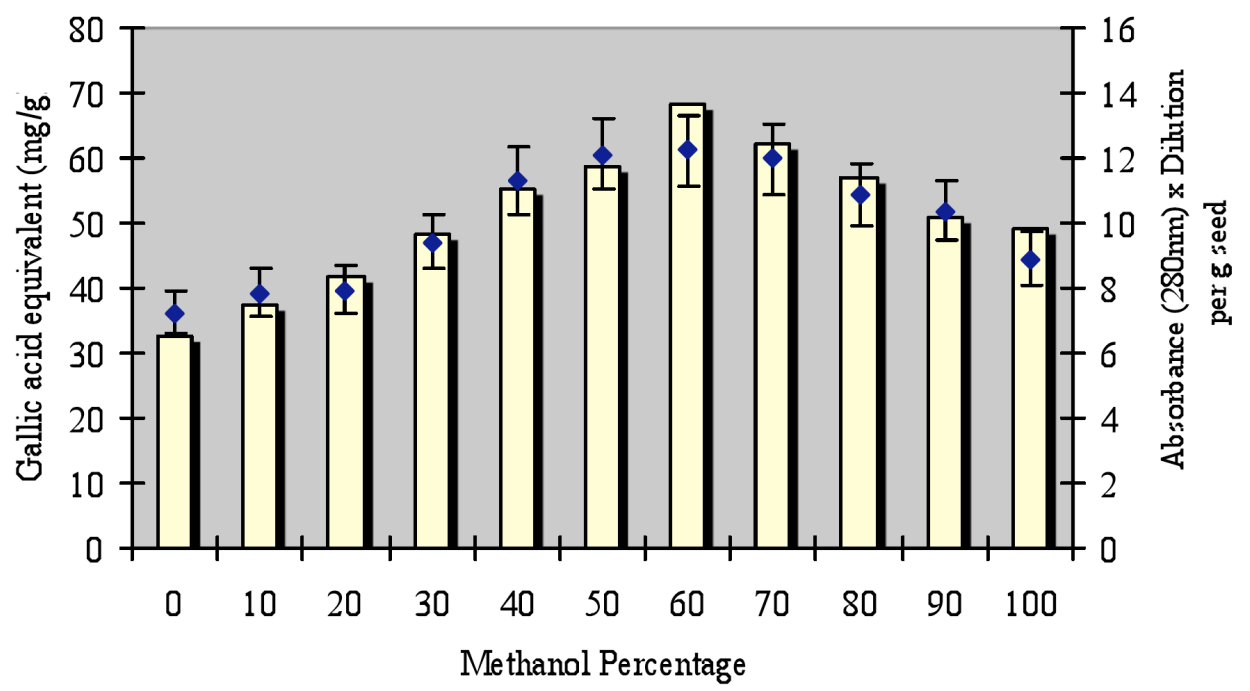

Fig. (2). Effect of methanol on the total phenol contents and absorbances at $280 \mathrm{~nm}$ of supernatants from dried guarana seeds.

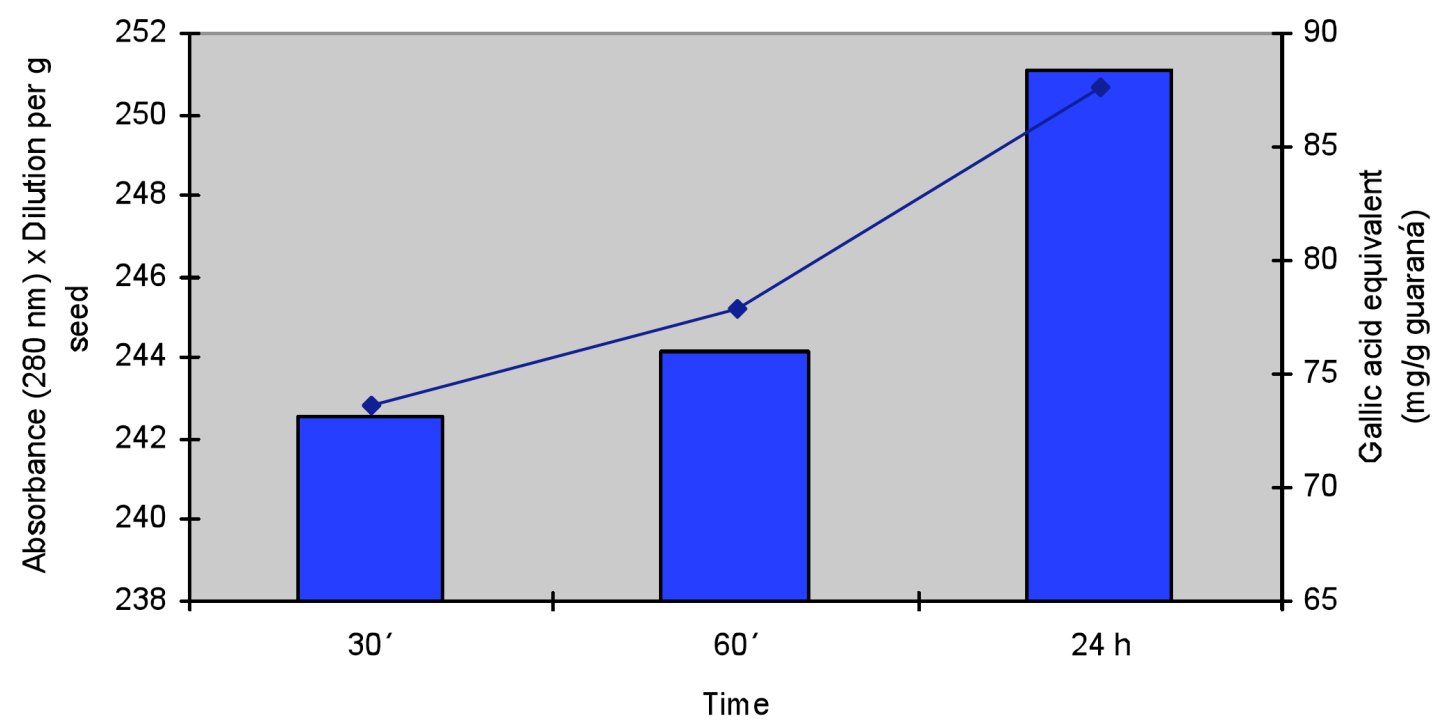

Fig. (3). Effect of the time in extraction of the total phenol contents and absorbances at $280 \mathrm{~nm}$ from dried guarana seeds. 


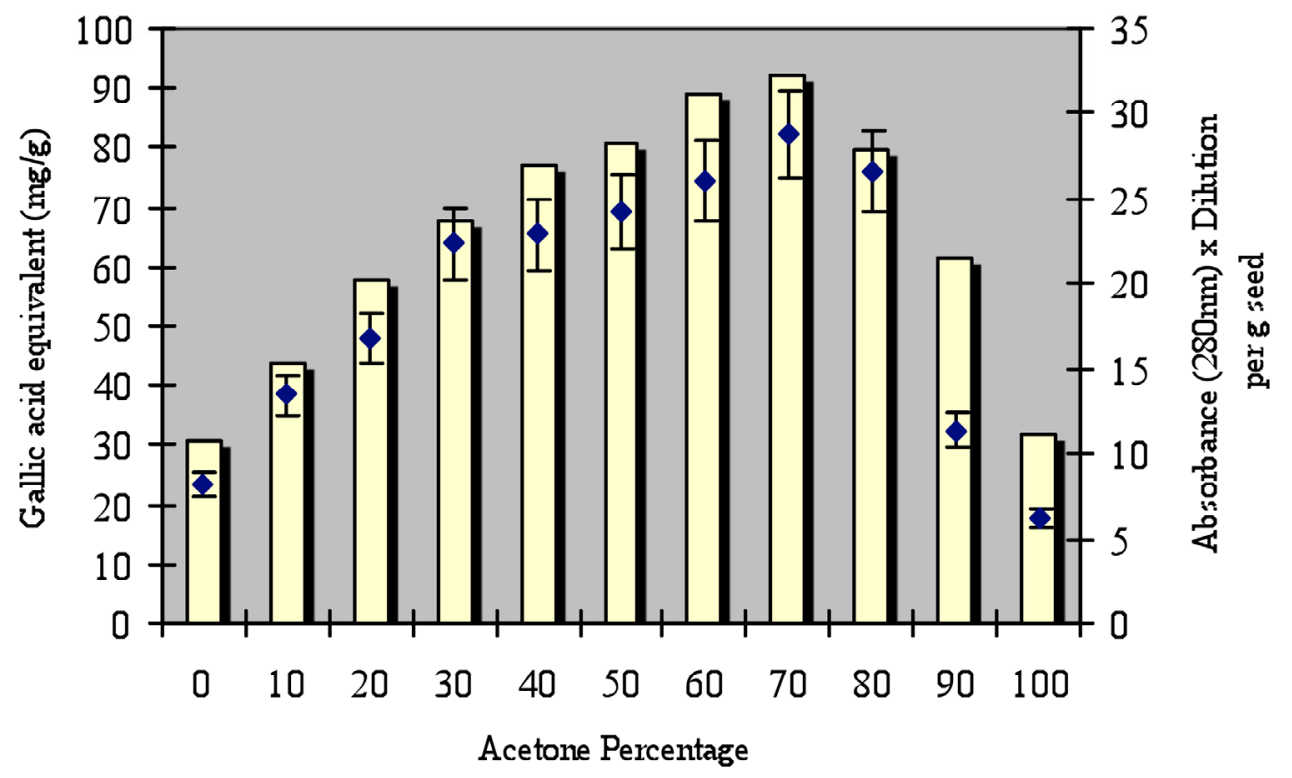

Fig. (4). Effect of acetone on the total phenol contents and absorbances at $280 \mathrm{~nm}$ of supernatants from dried guarana seeds.

the highest total phenol content (about $87.3 \mathrm{mg} \mathrm{GAE} / \mathrm{g}$ dry guarana seed powder) in the extracts (Fig. 4) $(P<0.05)$. Neither acetone nor de-ionized water alone was as effective as the $50 \%$ or $75 \%$ acetone solvents. The antioxidant activity of extracts when using $70 \%$ acetone solvent was the highest among the acetone solvents mixtures essayed $(P<0.05)$. The extracts from solvents containing $50 \%$ acetone or more, in general, had higher absorbance at $280 \mathrm{~nm}$, meaning that tannin extraction was effective when the extraction solvent contained $50 \%$ or more acetone.

Most catechins have a maximum absorption at around $280 \mathrm{~nm}$, and (+)-catechin was reported to be the major catechin monomer in guarana seeds [32]. The correlation between total phenol contents and total tannins (absorbance at $280 \mathrm{~nm}$ ) in guarana seeds extracts were significant $\left(\mathrm{r}^{2}=0.905, P<0.01\right)$. In a study with grape skin presented by Yilmaz and Toledo [33] showed significant correlations $\left(\mathrm{r}^{2}=\right.$ $0.814, P<0.01)$ between total phenol contents in the grape skin extracts and the total tannins measured as absorbance at $280 \mathrm{~nm}$.

A mono-component solvent system (water, ethanol, acetone or methanol) was not as efficient in extracting phenolic constituents of guarana seeds as an aqueous solution containing at least $50 \%$ water. Thus, resulted obtained of IPT and antioxidant activities showed that a select mixture of the water: acetone was as efficient solvent extractor. Results obtained above indicate that an acetonewater mixture is an effective solvent. This is in agreement with the study of Majhenic et al., [21], which reported that solvents mixed with water (such as $60 \%$ ethanol and $35 \%$ acetone) are better for extraction of caffeine and catechins from guarana seed than are pure solvents (such as methanol).

\subsection{GC-MS Analysis}

The isolation and quantification of phenolic compounds in plant material is a difficult task because of their chemical complexity (Fig. 5). The sensitivity and resolving power of capillary GC-MS make this technique particularly suitable for unambiguous detection of phenolic compounds in the hydrolysed samples. Silylation is the most widely used derivatization procedure for sample analysis by GC. The derivatives are generally less polar, more volatile and more thermally stable. The silylation reaction is a nucleophilic substitution reaction. Chu et al., [22] and Proestos et al., [25] propound the use of a mixture of TMCS and BSTFA (water bath at $80^{\circ} \mathrm{C}$ for $45 \mathrm{~min}$ ) to complete the derivatization. Several variables should be examined to determine its role in the derivatization procedure: 1) temperature; 2) reaction time; and 3) the amount of the silylating reagent required to complete the derivatization. In this study, the mixture HMDS: DMCS in pyridine was used because the derivatization step is carried out at ambient temperature in order to avoid the enolization process observed when BSTFA is used, due to the need to employ high temperature reactions $\left(80-90{ }^{\circ} \mathrm{C}\right)$. Carlson and Thompson [34] had extracted methylxanthines and polyphenols from guarana matrix samples with a heated phosphate buffer-methanol solution, and identified the methylxanthines theobromine, theophylline, and caffeine, and the polyphenols $(+)$-catechin and (-)-epicatechin, in the liquid chromatographic (LC) system, with a Nova-Pak C18 column eluted with phosphate buffer-methanol mobile phase $(\mathrm{pH}=3.50)$, monitored at 272 nm.

The GC oven temperature program, as well as the injector and detector temperatures used, was based on previous experience with the analysis of phenolic compounds in olives extract [35]. Data obtained showed excellent resolution between all compounds of interest. Molecular weights (MWs) and important ions present in the mass spectra of silylated phenolic compounds in the guaraná extracts examined are presented in Table 1. Three more phenolic compounds, Quercetin, (+)-Catechin and (-)Epicatechin were identified by the present method as TMS derivatives and the structures were confirmed by matching with the Wiley and NIST libraries. With the proposed method we identify nine phenolic compounds as well as fructose, glucose, citric acid and caffeine (Table 1). 


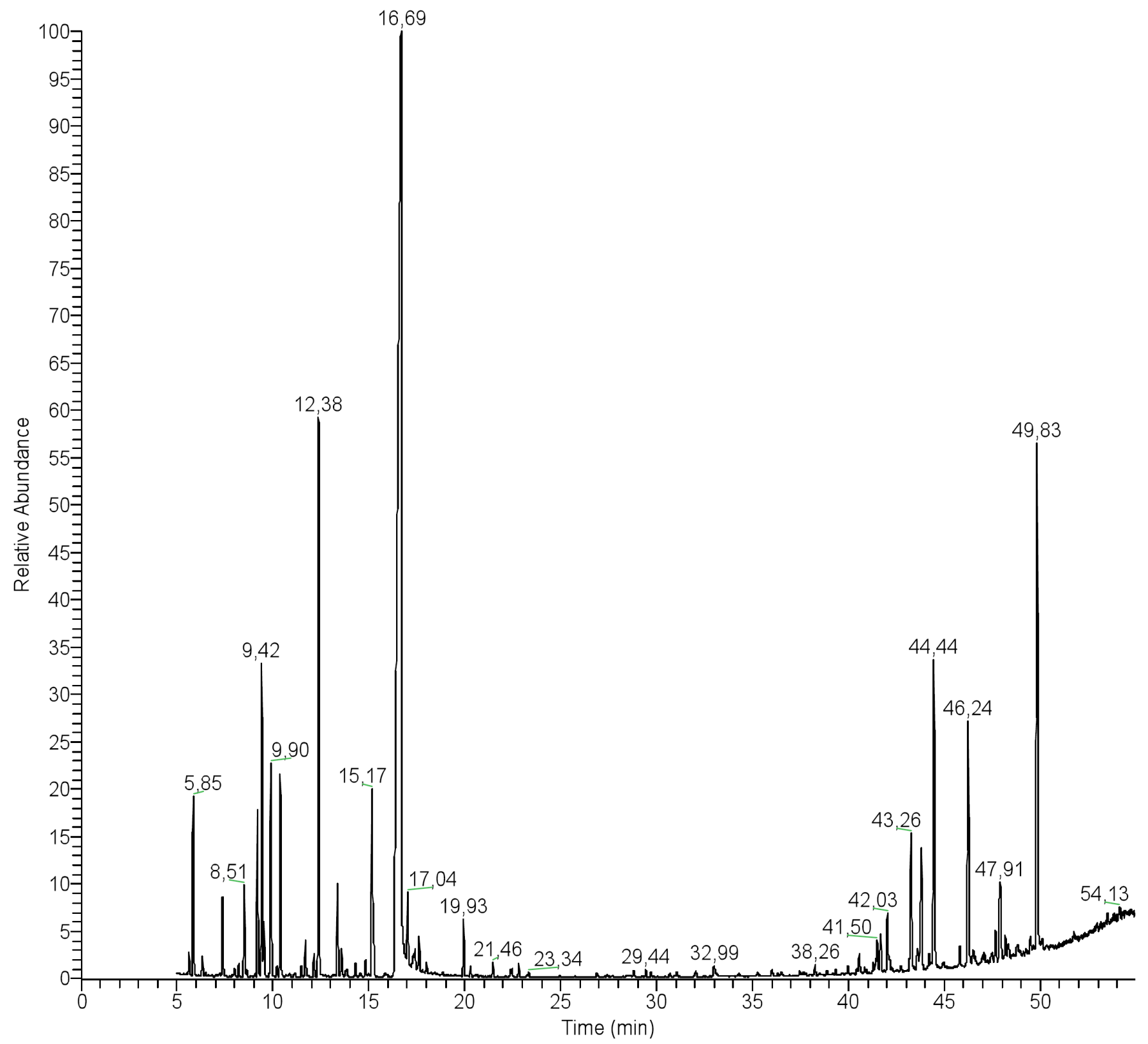

Fig. (5). CGC-MS analysis of phenolic compounds of an extract of guarana

\subsection{Total Phenolic Content and Total Antioxidant Capacity}

The total phenolic content of the guarana samples studied (powders, pericarp, pulp seeds, capsules and bar) is shown in Table 2. Though the origin of the different samples is completely different, the comparison of results is made only with indicative purposes. The phenolic content ranged from 30.77 to $124.12 \mathrm{mg}$ of $\mathrm{TAE} / \mathrm{g}$ of $\mathrm{DW}$. Seed pericarp exhibited the lowest total phenolic level $(30.77 \mathrm{mg}$ of $\mathrm{TAE} / \mathrm{g}$ ), whereas seeds powder and bar contained the highest one (105.56 and 124.12 of $\mathrm{TAE} / \mathrm{g}$ of $\mathrm{DW}$, respectively). Basile et al., [20] reported in fresh seeds obtained $8.43 \mathrm{mg}$ $\mathrm{GAE} / \mathrm{g}$ as the content of the phenolic in ethanol extract of the guarana from Brisighello (Verona, Italy) and Majhenic et al., [21] reported the contents of total phenols (based on guarana seed extracts) ranged from 119 to $186 \mathrm{mg}$ GAE/g extract. Phenolics are aromatic compounds that are hardly soluble in water, but easy soluble in ethanol, the increasing solubility of these compounds in hydroalcoholic solutions may affect the rate and the amount of its absorption. In fresh fruits and vegetables usually have very high moisture contents, and so typical processing of these fresh materials into juice or purees extracts primarily the water-soluble fractions [33]. However, a significant amount of the antioxidant are left in the residue after the aqueous fraction has been separated, being thus a second extraction necessary in order to get the total antioxidant capacity of the sample.

Following the analytical procedure described above we found values of catechol equivalent ranging from 0.35 to $2.23 \mathrm{mg} / \mathrm{g}$. By applying the ANOVA assay, we note that the commercialized capsule samples shown the greater variability, due possibly to the fact that these samples are 
Table 1. Molecular Weights (MWs) and Important Ions Present in the Mass Spectra of Silylated Phenolic Compounds in the Examined Guarana Extracts by GC-MS

\begin{tabular}{|c|c|c|c|}
\hline Compound & RT & MW* & Identified Ions $(\mathrm{m} / \mathbf{z})$ \\
\hline 3-hydroxybenzoic methyl ester & 6.33 & 224 & $209(100) 224(79) 177(60) 89(56) 149(33)$ \\
\hline Benzoic acid, 4 [trimethylsilyl) oxy-trimethylsilyl ester & 9.20 & 282 & $73(100) 267(98) 193(59) 223(57) 186(29) 282(28)$ \\
\hline 1,3,5 trihydroxybenzene, 3,4,5-trihydroxybenzoic acid (gallic acid) & 9.90 & 342 & $342(100) 327(74) 73(65) 328(24) 344(16)$ \\
\hline 3,5 dimethoxy-4-hydroxybenzoic acid (syringic acid) & 10.38 & 342 & $342(100) 327(56) 73(70) 237(14) 344(16) 310(10)$ \\
\hline Isovanillic acid & 13.37 & 312 & $297(100) 312(83) 267(65) 223(51) 282(41)$ \\
\hline Fructose & 13.58 & 540 & 73(100) 204(46) 217(30) 147(24) 437(22) \\
\hline Citric acid & 15.17 & 480 & $73(100) 147(29) 75(25) 273(20) 375(70)$ \\
\hline 3,4 dihydroxybenzoic acid (protocatechuic) & 15.90 & 370 & $73(100) 193(84) 370(38) 45(21) 355(22) 194(31) 311(11)$ \\
\hline Caffeine (1,3,7-trimethylxanthine) & 16.59 & 194 & 194(100) 109(38) 55(30) 67(24) 193(29) \\
\hline Glucose & 17.04 & 540 & 73(100) 204(86) 147(39) 191(38) 217(38) 361(24) \\
\hline Quercetin (3', 4', 5,7-tetrahydroxyflavonol) & 42.03 & 662 & $575(100), 647(32), 487(28) 662(5)$ \\
\hline$(+)$-Catechin $\left(5,7,3^{\prime}, 4^{\prime}\right.$-tetrahydroxyflavane $)$ & 43.26 & 650 & $368(100), 355,650,267,383,179,310$ \\
\hline (-)-Epicatechin & 44.44 & 650 & $368(100), 355,267,147,650$ \\
\hline
\end{tabular}

subjected to various elaboration procedures. However, there is no statistical difference in the phenolic content of bar samples as well as in the capsule and power samples.

Table 2. Total Phenolics, Catechol and Antioxidant Activity of the Guaraná Products ${ }^{\mathrm{a}}$

\begin{tabular}{|c|c|c|c|}
\hline $\begin{array}{c}\text { Guarana } \\
\text { Sample }\end{array}$ & $\begin{array}{c}\text { TPH }^{\mathrm{b}} \\
(\mathbf{m g} \text { of TAE/g) }\end{array}$ & $\begin{array}{c}\text { 'CT } \\
(\mathbf{m g} / \mathbf{g})\end{array}$ & $\begin{array}{c}\text { ORAC }_{\mathrm{FL}} \\
(\mu \mathbf{m o l ~ T E A C / g})\end{array}$ \\
\hline \hline Bar & $124.1 \pm 6.4$ & $2.20 \pm 0.1$ & $1079.6 \pm 36.6$ \\
\hline Seed pericarp & $30.7 \pm 1.0$ & $0.48 \pm 0.03$ & $356.2 \pm 12.1$ \\
\hline Seed powder & $105.6 \pm 4.5$ & $1.83 \pm 0.2$ & $987.3 \pm 33.8$ \\
\hline capsules & $57.6 \pm 5.4$ & $1.74 \pm 0.1$ & $558 \pm 38$ \\
\hline Powder & $73.2 \pm 3.3$ & $1.15 \pm 0.05$ & $906.1 \pm 39.5$ \\
\hline
\end{tabular}

${ }^{a}$ The results are presented as a mean standard deviation (SD) for triplicate analysis.

${ }^{\mathrm{b}} \mathrm{TPH}$ results are expressed in gallic acid equivalents (TAE)

${ }^{\circ} \mathrm{CT}$ results are expressed in catechin equivalents and $\mathrm{ORAC}_{\mathrm{FL}}$ results are expressed in Trolox equivalents (TEAC)

The antioxidant capacity (expressed as TEAC values) of guarana extracts is presented in Table 2 . It ranged from 356.22 to $1079.62 \mu \mathrm{mol}$ TEAC/g of DW. Though usually the seeds have the highest amount of total phenolics, an appreciable quantity is obtained in the cases of capsules, bars and powders. The highest value of TEAC found corresponds to the seed (sum pericarp seed more powder seed): $1343.53 \pm$ $45.9 \mu \mathrm{mol}$ TEAC/g of DW (mean \pm SD). The order of antioxidant activity in the different type guarana type samples tested was seeds $>$ bar $>$ powder $>$ capsules. The results of the antioxidant assay shown that the acetone $70 \%$ extract from guarana presents a considerably antioxidant scavenging activity against peroxyl radical (Table $\mathbf{2}$ ).

Results obtained in this study indicated an interesting antioxidant activity for all extracts from guarana. This is in agreement with the previous study of Majhenic et al., [21] which reported that the guarana seed extracts possess excellent radical-scavenging and antioxidant activities analyzed by DPPH assay and $\beta$-carotene-linoleic acid emulsion system. This is probably due to the phenolic compounds present in the extract, well documented in the case of other products as coffee, cocoa and tea [36].

A linear relationship was observed between TEAC and total phenolics or cathecol content. High correlation coefficients were found between the total phenolic content and antioxidant activity (r: $0.937, P<0.01$ ) for all the types of guarana tested measured by $\mathrm{ORAC}_{\mathrm{FL}}$ assay, and total phenolics and cathecol contents (r: $0.835, P<0.01)$.

\section{ACKNOWLEDGEMENTS}

Eugenia Marta Kuskoski thanks the CAPES (Coordenadoria de Aperfeiçoamento Ensino Superior, Brasil) for research support.

\section{CONFLICT OF INTEREST}

\section{Declared none.}

\section{REFERENCES}

[1] Gutteridge, J.M.; Halliwell, B. Antioxidants: molecules, medicines and myths. Biochem. Biophys. Res. Commun., 2010, 393(4), 561564.

[2] Halliwell, B. Biochemistry of the oxidative stress. Biochem. Soc. Trans., 2007, 35, 1147-1150.

[3] Spiteller, G. The important role of lipid peroxidation processes in aging and age dependent diseases. Mol. Biotechnol., 2007, 37(1) 512 .

[4] M.F.F. Chong, R. MacDonald, J.A. Lovegrove, Fruit polyphenols and CDV risk: a review of human intervention studies. British $J$. Nutr., 2010, 104(Suppl. 3), S28-S39.

[5] Ramos, S. Cancer prevention and chemotherapy: dietary polyphenols. Mol. Nutr. Food Res., 2008, 52(5), 507-526.

[6] Scalbert, A.; Manach, C.; Morand, C.; Rémési, C. Dietary polyphenols and the prevention of diseases. Crit. Rev. Food Sci. Nutr., 2005, 45(4), 287-306.

[7] Butt, M.S.; Sultan, M.T. Green tea: nature's defense against malignancies. Crit. Rev. Food Sci. Nutr., 2009, 49(5), 463-473. 
[8] Higdon, J.V.; Frei, B. Coffee and helath: a review of recent human research. Crit. Rev. Food Sci. Nutr., 2006, 46(2), 101-123.

[9] Kuskoski, E.M.; Fett, R.; García, A.; Troncoso, A.M. Propiedades quimicas y farmacologicas del fruto guaraná (Paullinia cupana). Vitae, 2005, 12(2), 45-52.

[10] Henman, A.R. Guarana (Paullinia cupana var. sorbilis): ecological and social perspectives on an economic plant of the central amozon basin. J. Etnopharmacol., 1982, 6(3), 311-338.

[11] Faria, J.J.P. Manual de Produçao do Guarana, Ediçao Sebrae, Cuiabá, MT, 2000.

[12] Weckerle, C.S.; Stutz, M.A.; Baumann, T.W. Purine alkaloids in Paullinia. Phytochemistry, 2003, 64(3), 735-742.

[13] Heckman, M.A.; Weill, J.; Mejia, E.G. Caffeine (1,3,7trimethylcanthine) in foods: a comprehensive review on consumption, functionality, safety, and regulatory matters. J. Food Sci., 2010, 75(3), R77.

[14] Smith, N.; Atroch, A.L. Guaraná's journey from regional tonic to aphrodiasic and global energy drink . Evid. Based Complement. Alternat. Med., 2010, 7(3), 279-282.

[15] Scholly, A.; Haskell, C. Neurocognitive effects of guaraná plant extracts. Drugs Fut., 2008, 33 (10), 869-874.

[16] Mattei, R.; Dias, R.F.; Espinola, E.B.; Carlini, E.A.; Barros, S.B.M. Guarana (Paullinia cupana): toxic behavioral effects in laboratory animals and antioxidant activity in vitro. J. Etnofarmacol., 1998, 60(2), 111-116.

[17] Sale, C.; Harris, R.C.; Delves, S.; Corbett, J. Metabolic and physiological effects of ingesting extracts of bitter orange, green tea and guarana at rest and during treadmill walking in overweight males. Int. J. Obesity, 2006, 30(5), 764-773.

[18] Sombra, L.L.; Gomez, M.R.; Olsina, R.; Martinez, L.D.; Silva, M.F. Comparative study between capillary electrophoresis and high performance liquid chromatography in 'guarana' based phytochemicals. J. Pharm. Biom. Anal., 2005, 36(5), 989-994.

[19] Edwards, M.G.M.; Farwell, D.W.; Oliveira, L.F.C.; Alia, J.M.; Hyaric, M.L.; Almeida, M.V. FT-Raman spectroscopic studies of guarana and some extracts. Anal. Chim. Acta, 2005, 532(2), 177186.

[20] Basile, A.; Ferrara, L.; del Pozo, M.; Mele, G.; Sorbo, S.; Bassi, P.; Montesano, D. Antibacterial and antioxidant activities of ethanol extract from Paullinia cupana Mart. J. Etnofarmacol., 2005, 102(1), 32-36.

[21] Majhenic, L.; Skerget, M.; Knez, Z. Antioxidant and anticmicrobial activity of guarana seed extracts. Food Chem., 2007, 104(3), 12581268.

[22] Chu, T.; Chang, C.; Zhan, J. Microwave-accelerated derivatization processes for the determinations of Phenolic acids by gas chromatography-mass spectrometry. Talanta, 2001, 54(6), 11631171.

[23] Zuo, Y.; Wang, C.; Zhan, J. Separation, characterization, and quantitation of benzoic and Phenolic antioxidants in American cranberry fruit by GC-MS. J. Agr. Food Chem., 2002, 50(13), 3789-3794.
[24] Cheng, H.; Zuo, Y.; Deng, Y. Separation and determination of flavonoids and other Phenolic compounds in cranberry juice by high-peformance liquid chromatography. J. Chromatogr. A, 2001, 913(1-2), 387-395.

[25] Proestos, C.; Boziaris, I.S.; Nychas, G-J.E.; Komaitis, M. Analysis of flavonoids and Phenolic acids in Greek aromatic plants: investing ation of their antioxidant capacity and antimicrobial activity. Food Chem., 2006, 95(4) 664-671.

[26] Singleton, V.L.; Orthofer, R.; Lamuela-Raventos, R.M. Analysis of total phenols and their oxidation substrates and antioxidants by means of Folin-Ciocalteu reagent. Methods Enzymol., 1999, 299, $152-178$.

[27] Magna, A.; Salomao, A.A.; Vila, M.M.D.C.; Tubino, M. Comparative study of two spectrophotometric reagents for catechol analysis in guarana seeds powder. J. Brazilian Chem. Soc., 2003, 14(1), 129

[28] Davalos, A.; Gómez-Cordovés, C.; Bartolomé, B. Extending applicability of the oxygen radical absorbance capacity (ORACfluorescein) assay. J. Agr. Food Chem., 2004, 52(1), 48-54.

[29] Prior, R.L.; Hoang, H.; Gu, L.; Wu, X.; Bacchiocca, M.; Howard, L.; Hampsch-Woodill, M.; Huanf, D.; Ou, B.; Jacob, R. Analisis for hydrophilic and lipophillic antioxidant capacity (oxygen radical absorbance capacity (ORAC (FL)) of plasma and other biological and food samples. J. Agr. Food Chem., 2003, 51(11), 3273-3279.

[30] Asuero, A.G.; Sayago, A.; Gonzalez, A.G. The correlation coefficient: an overview. Crit. Rev. Anal. Chem., 2006, 36(1), 4159.

[31] Asuero, A.G.; Gonzalez, G. Fitting straight lines with replicated observations by linear regression. III Weighting data. Crit. Rev. Anal. Chem., 2007, 37(3), 143-172.

[32] Marx, F. Analysis of guarana seeds II. Studies on the composition of the tannin fraction. Z. Lebensm. Unters. Forsch., 1990, 190(5), 429-431.

[33] Yilmaz, Y.; Toledo, R. Oxygen radical absorbance capacities of grape/wine industry bioproducts and effect of solvent types on extraction of grape seed polyphenols. J. Food Comp. Anal., 2006, 19(1), 41-48

[34] Carlson, M.; Thomson, R.D. Liquid chromatographic determination of methylxanthines and catechins in herbal preparations containing guarana. J. Ass. Off. Anal. Chem. Int., 1998, 81(4), 691-701.

[35] Rios, J.J.; Gil, M.J.; Gutierrez-Rosales, F. Solid-phase extraction gas chromatography-ion trap-mass spectrometry qualitative method for evaluation of phenolic compounds in virgin olive oil and structural confirmation of oleuropein and ligstroside aglycons and their oxidation products. J. Chromatogr. A, 2005, 1093(1-2), 167176.

[36] Richelle, M.; Tavazzi, I.; Offord, E. Comparison of the antioxidant activity of commonly consumed polyphenolic beverages (coffee, cocoa, and tea) prepared per cup serving. J. Agr. Food. Chem., 2001, 49(7), 3438-3442. 